\title{
THREE CDNA CLONES FOR BARLEY LEAF ACYL CARRIER PROTEINS I AND III
}

\author{
by
}

\author{
LARS HANSEN
}

\author{
Department of Physiology, Carlsberg Laboratory, \\ Gamle Carlsberg Vej 10, DK-2500 Copenhagen Valby \\ and \\ Institute of Genetics, University of Copenhagen, \\ Øster Farimagsgade 2A, DK-1353 Copenhagen K
}

\begin{abstract}
Keywords: Fatty acid synthetase, sequence homology, nuclear coded chloroplast protein, transit peptide
\end{abstract}

\begin{abstract}
Three cDNA clones for acyl carrier protein (ACP) isolated from a $\lambda g t 11$ cDNA library prepared from greening barley seedling leaves using a $66^{\prime}$ mer oligonucleotide probe have been sequenced. pACP 2 (371 bases) and pACP 11 (768 bases) code for the 90 amino acid chloroplast located ACP I. pACP 1 ( 520 bases) codes for a hitherto unknown protein with 83 amino acids that has been designated ACP IlI. The primary structure of its 27 amino acid partial transit peptide bears no obvious similarities to the transit peptide of ACP I. Northern analysis of immature caryopses' poly $A^{+}$RNA using the 66'mer probe reveals the presence of an ACP mRNA of significantly smaller size than the ACP mRNAs detectable in the leaf.
\end{abstract}

\section{INTRODUCTION}

The majority of the reactions which take place during synthesis of acyl lipids in plastids requires that the growing chain is presented to the enzymes while bound through a thioester linkage to the prosthetic group of a small cofactor-like protein aptly named acyl carrier protein (ACP). The limited presently available evidence suggests that ACP is synthesized as follows (11, 16, 17, 24, 28, 30, 35): Nuclear encoded messages are translated in the cytosol into (apo)-preACP which undergoes two types of processing. That is, the prosthetic group 4'-phosphopantetheine is added to a serine residue. The resulting (holo)preACP is then imported into a plastid compart- ment during which the amino terminal residues forming the transit peptide are cleaved in one or perhaps two steps to yield the mature protein (holo)-ACP.

Several years ago this laboratory demonstrated (17) by primary structure analyses that barley chloroplasts contain two mature ACPs (I and II). They were inferred to be encoded by different genes. Do these ACPs have different functions and if so what? In pursuit of these questions, ACP cDNAs have been isolated from barley leaves. Sequencing reveals that two of them code for ACP I while a third codes for a hitherto unknown ACP III.

Abbreviations: $\mathrm{A}=$ absorption; $\mathrm{ACP}=$ acyl carrier protein; $\mathrm{DNase}=$ deoxyribonuclease; $\mathrm{kb}=$ kilobase; $\mathrm{kD}=\mathrm{kilo}$ Dalton; MOPS = 3-[N-morpholino]propanesulfonic acid; $\mathrm{OD}=$ optical density; RNase = ribonuclease; $\mathrm{SDS}=$ sodium dodecyl sulfate. 


\section{MATERIALS AND METHODS}

\subsection{Enzymes and chemicals}

The restriction endonuclease Eco RI, Klenow polymerase, DNA I polymerase (endonuclease free), alkaline phosphatase from calf intestine, T4 DNA polynucleotide kinase, deoxynucleotides and dideoxynucleotides were from Boehringer Mannheim, FRG. T7 polymerase and the sequencing kit Sequenase were from United States Biochemical Corporation, Cleveland, USA and DNase I (grade II) from Sigma, St. Louis, USA. Poly U Sepharose 4B and G-50 Fine Sephadex were from Pharmacia Fine Chemicals, Uppsala, Sweden and guanidinium hydrochloride from Merck, Darmstadt, FRG. Radioactive nucleotides and nylon filters (Gene Screen Plus) were from New England Nuclear Research Products, USA and nitrocellulose filters, BA85, from Schleicher \& Schuell, FRG.

\subsection{Biological materials}

The barley (Hordeum vulgare) used was cv. Svalöfs Bonus. Poly $\mathrm{A}^{+}$RNA isolated from immature barley caryopses 30 days after flowering was a gift from ROBERT LEAH. Department of Biotechnology, Carlsberg Research Center. Spinach leaf material came from commercial, field grown plants available in the local market. Only the very youngest leaves were used.

The pUC 18 plasmid was multiplied in E. coli strain DH5 $\alpha$ (a modification of DH5 (13)): genotype; $\mathrm{F}$, end $\mathrm{A} 1$, hsd $\mathrm{R} 17\left(\mathrm{r}_{\mathrm{k}}, \mathrm{m}_{\mathrm{k}}{ }^{+}\right)$, sup E44, thi-1, $\lambda$-, rec A1, gyrA96, relA1, \$80lacZ $\Delta \mathrm{M} 15$. Screening and growth of $\lambda \mathrm{gt} 11$ were accomplished using E. coli strain Y1090 (American Type Culture Collection no. 37194): genotype; slac $\mathrm{U} 169$, proA ${ }^{+}, \Delta l o n, \operatorname{ara\mathrm {D}139}$, strA, sup F[trpC22::Tn10] (pMC9) (15). DH5a was grown in LB medium ( $1 \%$ Difco Bacto tryptone, $0.5 \%$ Difco Bacto yeast extract, $1 \% \mathrm{NaCl}$ ) with ampicillin $\left(50 \mu \mathrm{g} \cdot \mathrm{ml}^{-1}\right)$, and when necessary 5-bromo-4-chloro-3-indolyl- $\beta$-D-galactopyranoside (X-gal, $\left.50 \mu \mathrm{g} \cdot \mathrm{ml}^{-1}\right)$. For strain Y1090 the LB medium was supplemented with $10 \mathrm{mM}-\mathrm{Mg}$ $\mathrm{SO}_{4}$ and ampicillin $\left(50 \mu \mathrm{g} \cdot \mathrm{ml}^{-1}\right)$. The top agarose for plaque formation was LB medium with $10 \mathrm{~mm}-\mathrm{MgSO}_{4}$ and $0.7 \%$ agarose.

\subsection{Plasmids and $\lambda$ vectors}

Subcloning was accomplished using pUC 18 (39). The plasmids were treated with alkaline phosphatase according to (22) before use in the ligations. The $\lambda$ gt 11 (lac5, cI857, nin 5, S100) cDNA library was a kind gift from LISBETH HøNBERG, Department of Physiology, Carlsberg Laboratory. The library was constructed from greening barley seedling leaf RNA recovered after two cycles of oligo dT cellulose column chromatography.

\subsection{Isolation of leaf RNAs}

The procedure for isolation of RNA from barley and spinach leaves is based on a modification of (7) as described by HøYER-HANSEN et al. (18). The barley caryopses were germinated in vermiculite moistened with tap water. Greening leaves (100-300 grams) were harvested after 6 days growth in the dark plus 6 hours in continuous white light $\left(2.4 \cdot 10^{3} \mathrm{~lx}\right)$ at $23{ }^{\circ} \mathrm{C}$ by cutting $3-4 \mathrm{~cm}$ above the vermiculite to avoid any fungal contamination. Alternatively, the seedlings were grown with alternating cycles of 14 hours light $\left(15^{\circ} \mathrm{C}, 2.3 \cdot 10^{4} \mathrm{~lx}\right)$ and 8 hours darkness $(10$ ${ }^{\circ} \mathrm{C}$ ) for a period of 3 weeks. The latter are designated light grown leaves.

To obtain an enrichment of poly $\mathrm{A}^{+}$RNA, poly U Sepharose $4 B$ column chromatography was carried out as described by BRANDT and INGVERSEN (3). $A_{260}$ and $A_{280}$ measurements revealed that the typical yield of total RNA was 5-7 OD units per gram wet weight leaves, and poly $\mathrm{A}^{+}$RNA was $1 \%$ of the total RNA. The quality of the RNA was examined by gel electrophoresis and by in vitro translation using a rabbit reticulocyte lysate (Amersham N. 90) according to the manufacturers specifications.

\subsection{Construction of the probe for screening of cDNA libraries}

Based on a cDNA sequence for ACP I isolated from spinach leaves (D. SCHERER, personal commun., (30)), a 66 nucleotide long probe was constructed to the highly conserved region of the ACP molecule spanning from amino acid 38-59 in the barley sequence (16). The latter differs by only two amino acids in this region from the 


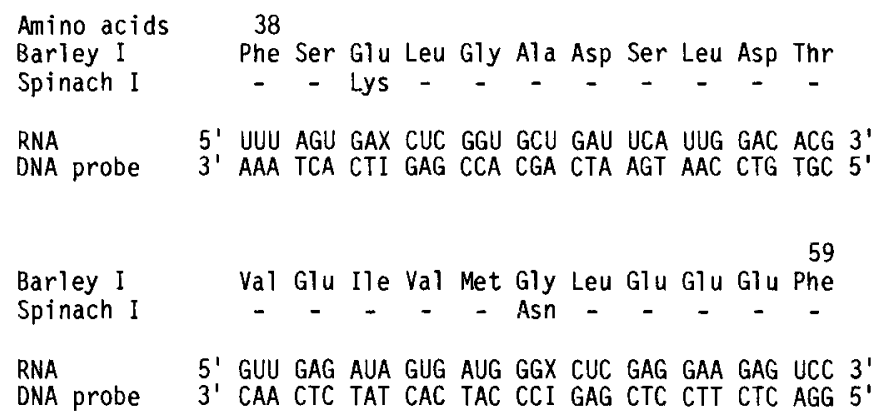

Figure 1. A highly conserved sequence in barley ACP I and spinach ACP I $(16,20)$ allows construction of a 66 base long oligonucleotide probe. The known spinach RNA codons (30) are shown except for amino acids 40 and 54 in which cases codons for the barley amino acids are substituted. $\mathrm{X}$ means more than one base possible, therefore inosine has been used in the DNA probe.

spinach sequence (Figure 1). In the latter two positions, codons were substituted having deoxyinosine (25) in the third position to account for code degeneracy. The probe was synthesized from O-methyl phosphoramidites using an Applied Biosystem Model 380A synthesizer. The products were decoupled as described in the manual, and desalted on a G-50 Fine Sephadex column. The 66 'mer was separated from incomplete sequences because of immature termination on a $12.5 \%$ preparative polyacrylamide 7 M-urea gel. The oligonucleotide was eluted by washing two or three times for $30 \mathrm{~min}$ with sterile deionized water at $40{ }^{\circ} \mathrm{C}$, thereafter phenol extracted, desalted and the concentration determined from absorption measurements. To examine the purity of the $66^{\prime}$ mer, end-labelling was done using T4 DNA polynucleotide kinase and $\gamma_{-}{ }^{32} \mathrm{P}$-ATP $\left(222 \mathrm{TBq} \cdot \mathrm{mmol}^{-1}\right)$ according to (22). The end-labelled products and size markers were separated on an $8 \%$ sequencing gel.

\subsection{Analyses of poly $\mathrm{A}^{+}$RNA}

The isolated poly $\mathrm{A}^{+}$RNA was analyzed by denaturing gel electrophoresis in $1 \%$ agarose, 1×MOPS (20 mM-3(N-morpholino)propanesulfonic acid, $5 \mathrm{~mm}$-sodium acetate, $1 \mathrm{~mm}$ $\mathrm{Na}_{2}$ EDTA, $\mathrm{pH} 7.0$ ) and $6 \%$ formaldehyde. The loading buffer, which was $50 \%$ deionized formamide, $6 \%$ formaldehyde and $1 \times$ MOPS containing the RNA, was heated at $65^{\circ} \mathrm{C}$ for $15 \mathrm{~min}$ before applying to the gel. After electrophoresis using $1 \times$ MOPS circulating buffer the gels were stained with ethidium bromide. RNA was transferred overnight to nylon filters using $10 \times \mathrm{SSC}$ (1.5 M-NaCl, $0.03 \mathrm{M}$-sodium citrate) after the formaldehyde had been washed out of the gel with running deionized water. The filters were prehybridized at least 4 hours at $65^{\circ} \mathrm{C}$ in $5 \times \mathrm{SSC}$, $0.2 \%$ Ficoll $400,0.2 \%$ polyvinylpyrrolidone, $0.2 \%$ bovine serum albumin, $1 \%$ sodium dodecyl sulfate (SDS) and $100 \mu \mathrm{g} \cdot \mathrm{ml}^{-1}$ of denatured, sheared DNA. The 16-36 hour hybridizations were done under the same conditions except for the addition of $2-4 \mathrm{ng} \cdot \mathrm{ml}^{-1}$ of the end-labelled probe $\left(10^{7}-10^{8} \mathrm{cpm} \cdot \mu \mathrm{g}^{-1}\right.$ probe, see section 2.5$)$. The washing conditions for these Northern hybridizations were $2 \times 5 \mathrm{~min}$ in $5 \times \mathrm{SSC}$ at room temperature followed by $2 \times 30 \mathrm{~min}$ in $5 \times \mathrm{SSC}$, $1 \% \mathrm{SDS}$ at $65^{\circ} \mathrm{C}$ and finally a rinse in $5 \times \mathrm{SSC}$ at room temperature. The filters were exposed using either Kodak X-Omat AR or Amersham Hyperfilm MP with intensifying screens at -70 ${ }^{\circ} \mathrm{C}$ for 2-6 days.

\subsection{DNA preparation}

Plasmid DNA preparations from E. coli were accomplished by the alkaline lysis method of BIRNBOIM and DoLY (2) followed by $\mathrm{CsCl}$ equilibrium centrifugation for large scale preparations. DNA fragments were either electroeluted in dialysis tubing using TE (10 mM-Tris $\mathrm{pH} 7.5$, 1 mM-EDTA) or recovered from low melting agarose (22), and purified by phenol extractions 
and ethanol precipitations. Alternatively, the ligation was carried out directly in the low melting agarose without further purification.

Preparation of $\lambda$ DNA was done on a small scale by a modification of the method described in ref. (9). An infected cell culture of $100 \mathrm{ml}$ was incubated at $37{ }^{\circ} \mathrm{C}$ with vigorous shaking for $51 / 2-6$ hours. Two ml chloroform was added and the suspension kept at $4{ }^{\circ} \mathrm{C}$ overnight. The cell debris and chloroform were spun down, and the supernatant adjusted to $10 \mu \mathrm{g} \cdot \mathrm{ml}^{-1}$ of DNase I and incubated for $30 \mathrm{~min}$ at $37^{\circ} \mathrm{C}$. The culture was recentrifuged and the supernatant combined with one volume $20 \%$ polyethyleneglycol, $2.5 \mathrm{M}-\mathrm{NaCl}$ and left on ice for $1 / 2^{-1}$ hour. The phages were pelleted by centrifugation and resuspended in 1-2 $\mathrm{ml}$ of $10 \times \mathrm{TE}$. SDS was added to $1 \%$ before incubation at $68{ }^{\circ} \mathrm{C}$ for $15 \mathrm{~min}$. Phenol extraction of the phages until no interphase was left and ethanol precipitation followed. The resulting naked phage DNA was resuspended in sterile TE and $10 \mu \mathrm{g} \cdot \mathrm{ml}^{-1} \mathrm{RNase}$ A.

\subsection{Screening the $\lambda$ gt11 cDNA library}

The cDNA library made from greening barley leaves was screened with the 66 base long probe using the hybridization conditions specified in section 2.6. This involved plaque lifts (1) from $22 \times 22 \mathrm{~cm}$ plates using nitrocellulose filters. Each plate contained about $10^{5}$ plaques and had confluent or semiconfluent lysis. The positive plaques were isolated by cutting out small blocks of agarose, eluting the phages in $0.1 \mathrm{M}-\mathrm{NaCl}, 10$ mM-Tris pH 7.5, 10 mM- $\mathrm{MgSO}_{4}$ and 2\% gelatine and rescreening by new plaque hybridizations on small $83 \mathrm{~mm}$ petri dishes containing typically 50-500 plaques. The rescreening continued until all the plaques were positive. Then small scale preparations of $\lambda$ DNA were made (see section 2.8) from the selected positive phages. The resulting DNA was digested with Eco RI and the inserts after recovery from low melting agarose were ligated into pUC 18.

\subsection{Sequencing and analysis of the cDNA clones}

The sequencing of the isolated cDNA clones was done by the dideoxynucleotide method (29) on double stranded plasmid DNA $(6,14)$ using Klenow polymerase or a modification of the method (36) employing T7 polymerase. Either the universal primers for pUC sequencing or appropriate ones synthesized by the method described in section 2.6 were used. The radioactive label was $\alpha-{ }^{35} \mathrm{~S}-\mathrm{dATP}\left(51.8 \mathrm{TBq} \cdot \mathrm{mmol}^{-1}\right)$. Sequence data were analysed according to QUEEN and KORN (27).

\section{RESULTS}

\subsection{Northern analysis}

The first step in isolating barley leaf ACP cDNA was to ascertain that the poly $\mathrm{A}^{+} \mathrm{RNA}$ preparations contained the appropriate $\mathrm{mRNA}$ species. Initially, small oligonucleotide probes covering amino acids 1-5, 50-54 and 56-62 in barley ACP I (16), which were known to hybridize to rape (Brassica napus) embryo mRNA (A.R. SLABAS, personal commun., (35)), did not hybridize to barley leaf mRNA. This was presumably due to the low level of ACP mRNA in leaves $(17,20)$, and made it desirable that a longer, more specific probe should be used. This became possible when the cDNA sequence for spinach leaf ACP I was available (D. SCHERER personal commun., later 30 ). The constructed 66 'mer (Figure 1 ) readily hybridizes to poly $\mathrm{A}^{+}$ RNA from barley leaves (Figure 2, right). A band at $1020-1050$ bases is present in both the greening and light grown leaf preparations whereas a smaller band at 800 bases occurs in that from immature caryopses. The band in the spinach preparation is intermediate in size, that is 930 bases. These bands become increasingly more difficult to detect on the filters as the stringency at which the hybridizations are carried out decreases, due to increasing non-specific binding of the 66'mer to the ribosomal RNA bands.

\subsection{Characterization of three positive clones}

The lengths of the barley cDNA inserts in the 22 positive clones isolated from the $\lambda \mathrm{gt} 11$ library were found to range from $300-800$ bases when small scale DNA preparations were digested and size fractionated by gel electrophoresis. Three of the clones were selected for detailed study, namely pACP 1, pACP 2 and pACP 11. To 


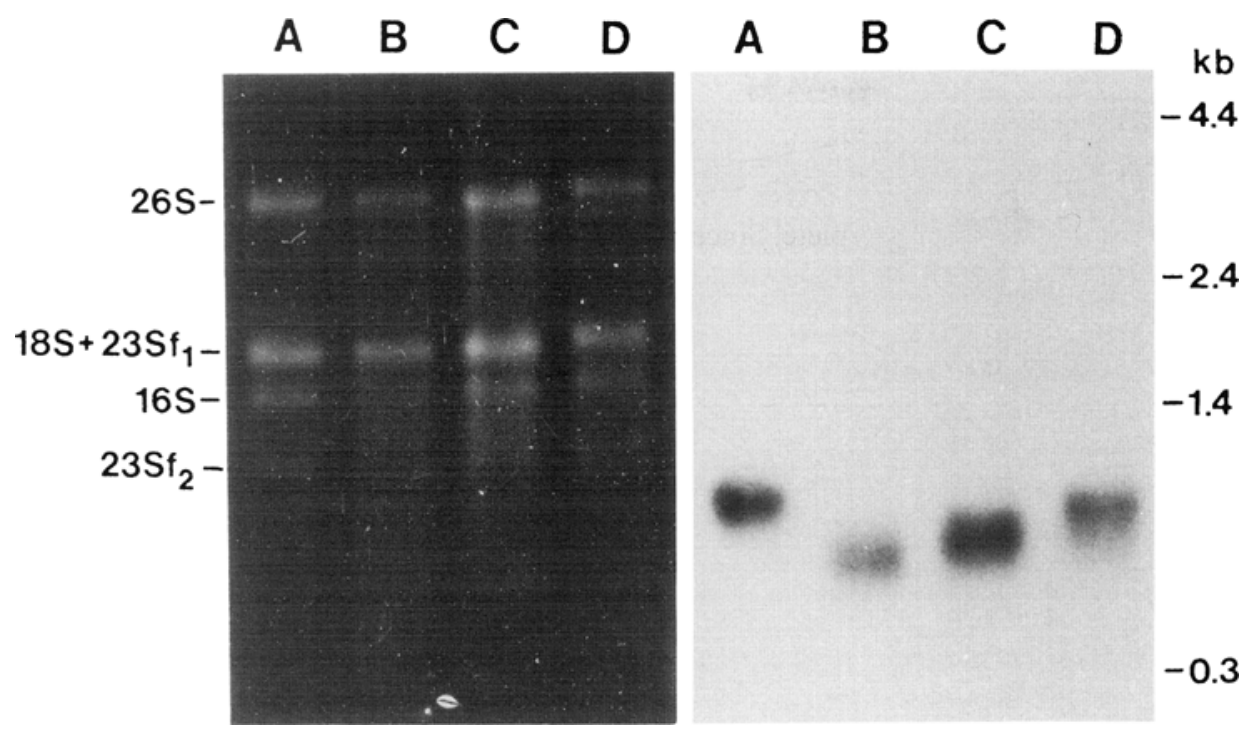

Figure 2. Northern analysis of poly $\mathrm{A}^{+} \mathrm{RNA}$ isolated from barley and spinach. The left panel is a denaturing agarose gel stained with ethidium bromide, the right panel is an autoradiogram of a Northern blot hybridization of the same gel. The probe was the end-labelled $66^{\prime}$ mer. In each lane $5 \mu \mathrm{g}$ poly A+ RNA was loaded. Lane A: greening barley seedling leaves; B: immature barley caryopses; C: young spinach leaves; D: light grown barley seedling leaves (see section 2.2). Ribosomal RNA bands are visible in the agarose gel: $18 \mathrm{~S}$ and $26 \mathrm{~S}$ come from cytoplasmic ribosomes, the two fragments of $23 \mathrm{~S}\left(23 \mathrm{Sf}_{1}\right.$ and $23 \mathrm{Sf}_{2}$ ) and $16 \mathrm{~S}$ come from chloroplast ribosomes (26).

accomplish this the inserts were subcloned into pUC 18. The universal primers for pUC sequencing in the regions flanking the inserts and the poly $A^{*}$ tail in pACP 1 served as the initial primers. Since the entire inserts of the two longer clones could not be sequenced from these primers, three additional sets of primers coding for both strands were synthesized (Figure 3). Using these primers all three clones were completely sequenced in both directions.

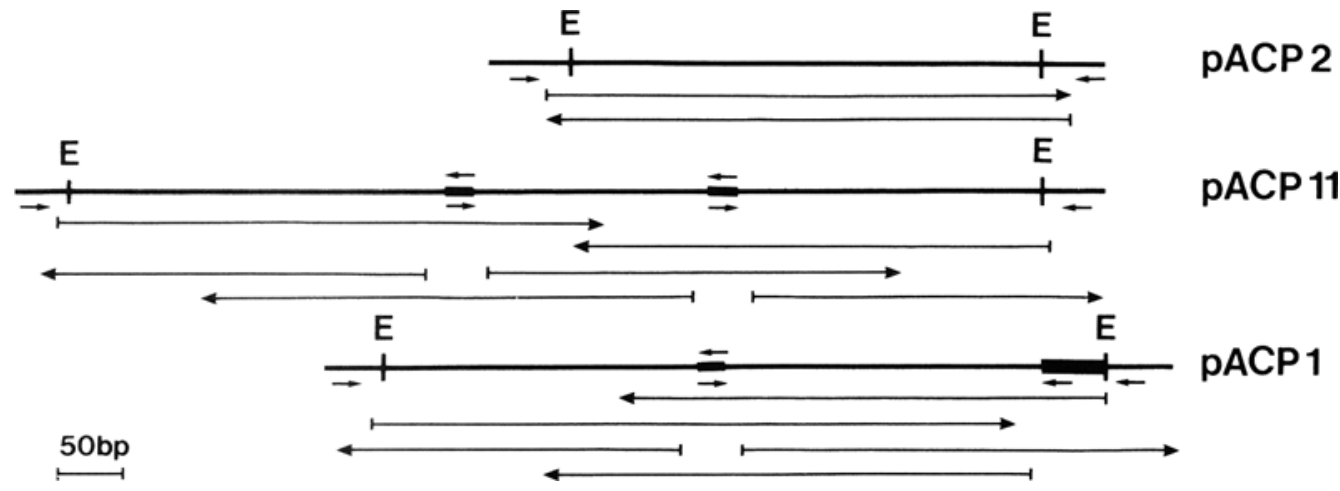

Figure 3. Strategy for sequencing the three ACP clones. Ends of the clones are marked by E, the Eco RI site in pUC 18. Thin blocks and short arrows represent the priming sites plus direction. The poly $\mathrm{A}^{+}$tail is shown by the thick block in pACP I which was also used for priming. A size scale is included in the bottom left corner. 
I: 78 ACCCATG GOG CAC TGC CTC GCC GCC GTT TCC TCC TTC TCG CCG TCC GCC GTC CGC CGG CGG 138

I: $\quad$ Met Ala His Cys Leu Ala Ala Val Ser Ser Phe Ser Pro Ser Ala Val Arg Arg Arg

I: 139 CTG TCC AGC CAG GTG GCT AAT GTA GTT TCG AGC CGG AGC TCA GTT TCT TTC CAT AGC CGG 198

II I: Leu Ser Ser Gin Val Ala Asn Val Val Ser Ser Arg Ser Ser Val Ser Phe His Ser Arg

199 CAG ATG AGC TTT GTA TCC ATC AGT TCA AGA CCG AGT TCG CTT CGG TTT AAG ATT TGT TGT 258 CTC TCT TTC TCC GGT GCA AGG AGG GGC AAT GCA TTT CTT CGC CTG CAG CCA GTG CCA ATG Gln Met Ser Phe Val Ser Ile Ser Ser Arg Pro Ser Ser Leu Arg Phe Lys Ile Cys Cys

319 AAG AAG CAG CTG GCA GTC CCT GAT GGT ACA CCT GTC ACA GCG GAG TCG AAA TTC ICC GAA 378

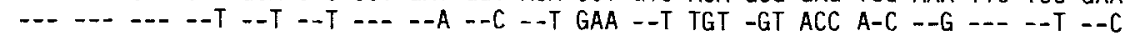
Lys Lys Gln Leu Ala Val Pro Asp Gly Thr Pro Val Thr Ala Glu Ser Lys Phe Ser Glu

379 CTT GGT GCC GAC TCA CTA GAC ACG GTT GAG ATT GTG ATG GGC CTC GAG GAA GAG ITC AAC 438

II :

I:

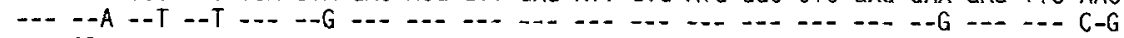
Leu Gly Ala Asp Ser Leu Asp Thr Val Glu Ile Val Met Gly Leu Glu Glu Glu Phe Asn

II :

I: 439 ATC ACT GTT GAT GAA ACA AGC GCG CAG GAC ATT GCA ACC GTG CAG GAT GCA GCG AAC CTT 498

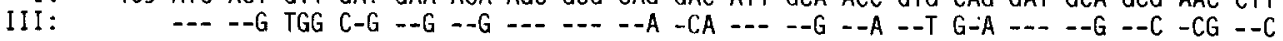
Ile Thr Val Asp Glu Thr Ser Ala Gln Asp Ile Ala Thr Val Gln Asp Ala Ala Asn Leu - - Trp Gin - - - _ - Ala - - - Glu - - Thr -

I: 499 ATC GAG AAG CTT GTG ACA GAG AAG ACC GCA TAA GCGCCTAGGTTCATTGGACAGCTTTAGAAGGCAAA 566

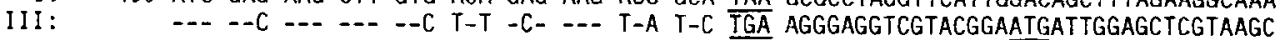
Ile Glu Lys Leu Val Thr Glu Lys Thr Ala - Asp - - - Ser Ala - Ser Ser

\section{(1)}

I: 567 GGTGTCATCTGGATCTGTGGACTTCTGATTTITCGGTCGCATTTGGGGCGAGAGAAMATAATTTATGGACAGCTTTGCA 645 II1: TAGTAGTCCTACCTTGGGTGATCCTTGTTGTTCGTTATIATATGGTGGGTTGGTGATTTTCTCAGGACTATTGTCTCC

$$
\text { (2) }
$$

I: 646 ITCAGTCTATGTTGTGTGTTCATTGCCATTTGTTCTITCTICATCCTCTCGAGATTTTGTGTTGTTGCTGCGGGTTAAT 724 III: TGCTGTGTGTAATAAGATAAT IGGTGAAGTATGTAAGCTGTTGACATCTAAGTTCCTAGTTTTCGTGCGGC (A) 51

\section{I: 725 TACCCAAAgGCTTCATAAACAAGCTAGgACCATGTCCTAAGTTC 768}

Figure 4. Two barley leaf acyl carrier proteins (ACP I and ACP III): CDNA and deduced amino acid sequences. Nucleotides representing possible regulatory sites in the flanking regions are shown in boxes. The cleavage site between the transit peptide and the amino terminal end of the mature ACP I is indicated by a thick arrow and the likely, analogous site for ACP III by a thin arrow. The stop codons are underlined. The star designates the serine residue to which the $4^{\prime}$-phosphopantetheine group is attached. A triangle represents the start of pACP 2 . The circled numbers in the 3 ' flanking region delimit three open reading frames. 


\subsection{1. $p A C P 11$ and $p A C P 2$}

The 371 bases of the insert in the small clone pACP 2 were identical to a segment of the 768 base insert in clone pACP 11. The deduced amino acid sequence starting from base 259 of pACP 11 matched exactly to the reported 72 amino terminal residues of ACP I (thick vertical arrow, Figure 4) (16). That amino acid 17 is a cystein was confirmed. The deduced amino acid sequence reveals that ACP I consists of 90 and not the 87 residues suggested on the basis of amino acid compositional analysis (16). The 258 bases 5' to those coding for ACP I can be translated into 86 amino acids, two of which are methionines. If the first of these represents the translational start, a transit peptide of 59 amino acids results versus one of 19 amino acids if the second methionine serves this function. On the basis of the length of other chloroplast transit peptides $(19,31)$, the former is believed to be most likely. In accord with this contention, the first ATG is part of a 9 base sequence in which 7 are identical to those in a consensus sequence encompassing the initiation codon in plants (21). This is not so for the other methionine. The present observations do not exclude, however, that the transit peptide of ACP I is even longer. Although a polyadenylation signal (10) occurs spanning bases 623-628 in the flanking 3' region, it is not followed by a poly A tail in the next 140 bases (Figure 4). Interestingly, the insert in the smaller clone pACP 2 stops at the same base. Within the downstream region two open reading frames for 30 and 36 amino acids are found. In neither case do the bases surrounding the ATG resemble the initiation consensus sequence referred to above. The same is true for the two small open reading frames in the +1 frame (bases 341-394 and 449-511) that occur within the coding region.

\subsection{2. $p A C P 1$}

The insert in clone pACP 1 is 520 bases long of which the first 331 can be translated into amino acids. The resulting primary structure can be aligned with that for ACP I by matching the conserved serine (* in Figure 4 ) and the stop codon. The presumed cleavage site for the removal of the transit peptide is indicated by the thin vertical arrow in Figure 4. The resulting amino terminal residues of the mature protein thus closely resemble those of other plant ACPs (see section 4). The resulting 27 amino acid transit peptide sequence is assumed to be incomplete. Since nine of the first 24 amino terminal residues of the obtained mature ACP differ from those reported for ACP II (17), we deduce that the insert in clone pACP 1 codes for a third ACP. The term ACP III has been used previously to tentatively designate a protein giving a minor peak in an ion exchange chromatography step carried out during purification of ACP I and II (17). Since no other experimental evidence is available to support that this protein is an $\mathrm{ACP}$, it is suggested that henceforth the name ACP III be used for the pACP 1 coded protein. Figure 4 reveals that the poly $A$ signal (38) at bases 656-661 (numbers correspond to pACP 11 in Figure 4), in contrast to those in the other two cDNAs, is followed 56 bases later by a tail of at least 51 adenines. The open reading frame translating into 49 amino acids in the 3 ' region lacks the consensus initiation secuence.

\section{DISCUSSION}

The synthesis of $\mathrm{C}_{16}$ and $\mathrm{C}_{18}$ carbon chains by fatty acid synthetase in plants requires $\mathrm{ACP}$ and the action of six enzyme activities for each successive $\mathrm{C}_{2}$ addition. At least two forms of each of four of the enzymes as well as of $\mathrm{ACP}$ have been isolated from single organs, such as leaves or seeds, where they are believed to be primarily localized in plastids $(5,12,16,32,33)$. In the case of barley and spinach leaves both ACP I and II have been shown to be in the chloroplasts $(17,23)$. That synthesis of the fatty acyl chains may be even more complex than the above statements imply can be inferred from the present data which identify an ACP III in barley leaves.

The homology between the overlapping cDNA sequences coding for the mature ACP I and III proteins is $71 \%$. In all but one of the 34 codons where only a single base differs, it is in the third position. Six of these changes result in different amino acids. The other 37 base discrepancies are located so that they give rise to an additional 16 variant amino acids. Besides these 
Figure 5. Comparison of the primary structure of mature plant ACP molecules. The sequence data for the barley ACP I, spinach ACP I and the three rape proteins have been determined by cDNA and/or amino acid sequencing; that for the barley ACP II and spinach ACP II proteins is from amino acid sequencing while that for the barley $\mathrm{ACP}$ III and turnip proteins is derived from cDNA sequences. Data is from references $(16,17,20,23,28,30,35)$. Barley: leaves of Hordeum vulgare; spinach: leaves of Spinacia oleracea; turnip: seeds of B. campestris (turnip-rape); and rape: embryoes of B. napus. Examination of the primary structures of mature ACPs deduced from 10 rape embryo cDNA clones (35) reveals that they can be divided into several classes. These can be correlated with the amino terminal sequences determined for rape seed ACPS I, II and III (34). Clones 28F10, 29C08 and 34C02, respectively, represent these three proteins in this figure. White letters on a black background are amino acids identical in all sequences. Shaded regions encompass amino acids differing among barley I, II and III, spinach I and II or the four Brassica (rape plus turnip) ACPs.

22 dissimilarities out of 83 , ACP I has seven extra residues at the amino terminal end. By comparison, no homology has been found in the cDNA sequences of the 3' flanking regions or in those corresponding to the transit peptides for ACP 1 and IIl. The extent of the disparities reveals that different genes determine ACP I and III.

Primary sequence differences among the amino terminal residues of ACP I and II combined with the fact that barley is a self fertilizing species and the cultivar studied is essentially homozygous led earlier to the deduction that these two proteins were products of different genes (17). If one now compares the first 24 residues of ACP II with those of the corresponding ones of ACP I or III as shown in Figure 5, 8 and 9 differences, respectively, are seen. At the nucleotide level this requires 2 or 3 base changes for 4 of the 8 and for 3 of the 9 codons. These analyses lead to the conclusion that ACPs I, II and III are encoded for by three different genes.

The primary structure of all available plant ACPs based on protein sequencing and/or deduced from cDNA sequences is presented in Figure 5. Of the 81 residues present in all nine proteins, $38(48 \%)$ are conserved. The following comparisons include the seven proteins for which complete sequences are available. When considered pairwise the homology among spinach ACP I and barley ACP I and III is 53-74\%, whereas that among the four Brassicas is $87-98 \%$. An analogous comparison among a spinach or barley sequence versus that of a Brassica yields $57-66 \%$ homology, while that between a barley ACP and either E. coli or Rhodobacter sphaeroides is 47 and $45 \%$, respec- tively $(8,37)$. Interestingly, Figure 5 reveals that the residues at which variation is observed among the barley ACPs are more often than not different ones than those at which the Brassica variation occurs. The same is true when the barley or Brassica ACPs are compared to the spinach ACPs even though only 19 residues are considered.

The much higher degree of homology among the three rape ACPs than among those from barley suggests that less than three genes determine rape seed ACPs. Rape (B. napus) is an amphidiploid that arose from crossing $B$. campestris and B. oleracea followed by chromosome doubling. If a single gene determined seed $\mathrm{ACP}$ in each progenitor, then the original B. napus must have been homozygous for two such genes. It is interesting to speculate that since the 10 cDNA rape sequences (35) are readily divided into two groups, these two groups (rape ACP I versus II and III) represent the two original rape seed ACP genes. That the second group can be subdivided presumably reflects mutational events giving rise to heteroalleles at this locus. The rape ACP III sequence shown in Figure 5 differs in only two amino acids from the turnip (B. campestris) sequence, both of which can be attributed to single base changes. Thus, one can hypothesize that the turnip seed ACP gene is the progenitor of that in rape (B. napus) determining the ACP II and III proteins. This in turns implies that the gene for rape seed ACP I came from $B$. oleracea.

Figure 6 presents the available deduced primary structures of plant ACP transit peptides. That the barley ACP I, spinach ACP I and turnip sequences are complete is in all cases an assump- 


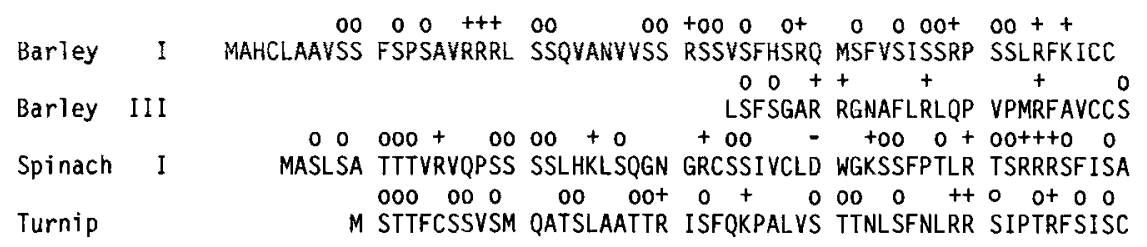

Figure 6. Complete and partial primary structures of plant $\mathrm{ACP}$ transit peptides as deduced from cDNA sequencing data. The positively charged amino acids are marked by $(+)$, the negatively charged one by $(-)$ and those with hydroxyl groups by (o). See Figure 5 text for explanation of barley, spinach and turnip as well as for sources of data.

tion arrived at as detailed in section 3.2.1. All three cDNA sequences continue upstream to their 5 ' ends with open reading frames corresponding to 27, 20 and 10 amino acids, respectively. No structural similarities are seen between barley ACP I and ACP III. The only possible exception is the $\mathrm{P}^{\cdots} \mathrm{RF}^{*} \mathrm{CC}$ motiv at the carboxy terminal end. Also no obvious likeness between barley ACP I and spinach ACP I or other published chloroplast transit peptides $(19,31)$ is readily detectable. On the other hand, the barley ACP I sequence is analogous to the aforementioned ones in having a high serine $(31 \%)$ and lysine plus arginine (14\%) amino acid content. That the turnip sequence is not akin to those of barley ACP I and spinach ACP I is hardly surprising since turnip rape ACP is believed to be localized in plastids of seeds, not in chloroplasts of leaves.

The most interesting fact to emerge from the present study is that three genes for ACP are expressed in greening barley seedling leaves. ACP I and II occur within chloroplasts. Is ACP III also present in the same organelle but in so much smaller quantities that it has escaped notice? Alternatively, ACP III may be in a different subcellular compartment. The presence of a third minor peak during isolation of $\mathrm{ACP}$ I and II from leaves that was not present when chloroplasts were the starting material (17), would support the latter notion. One possible explanation for the observation that the 66'mer probe hybridizes to a significantly smaller poly $\mathrm{A}^{+}$RNA (ca. 800 vs 1030 bases) isolated from immature caryopses than from leaves is that a fourth functional ACPgene exists in barley. Whether this gene is expressed in developing endosperm, aleurone or in the chloroplast containing hypodermis and inner pericarp of the caryopsis (4) is unknown at present. This finding is also of interest with respect to recently reported observations in rape and spinach. That is, a rape embryo cDNA probe did not hybridize to rape leaf poly $\mathrm{A}^{+}$ RNA although a mixed 14'mer oligonucleotide probe did (35). Similarly, a probe covering the entire 441 base coding region plus circa 50 bases of the 3' tail of spinach leaf ACP I cDNA did not hybridize to total RNA from spinach roots or immature seeds (30). This is surprising when the 66 'mer used in the barley organ cross hybridization experiment differs in only four bases plus two inosine substitutions from a 66 base segment of the just described spinach probe. Moreover, immature spinach seeds contain a protein that is recognized by antibodies to spinach leaf ACP I (23). Considerable tissue and cell specificity in the expression of members of the ACP multigene family is thus indicated. A careful separation of the mRNA from the tissues specialized in photosynthesis and in synthesis of lipid, starch and/or protein storage will be necessary to unravel this explicitness.

\section{ACKNOWLEDGEMENTS}

I would like to thank ANDERS BRANDT and KARL KRISTIAN THOMSEN for advise and helpful discussion and LisBeth HøNBERG for the $\lambda$ gt 11 cDNA library. PENNY vON WeTtSTEINKNOWLES is thanked for critical review of the manuscript and discussions throughout the project. Nina Rasmussen and AnN-Sofi SteinHOLTZ are thanked for preparation of the figures. 


\section{REFERENCES}

1. BENTON, W.D.\& R. W. DAVIS: Screening $\lambda g t$ recombinant clones by hybridization to single plaques in situ. Science 196, 180-182 (1977)

2. BiRNBOIM, H. C. \& J. DoLY: A rapid alkaline extraction procedure for screening recombinant plasmid DNA. Nucleic Acids Res. 7, 1513-1523 (1979)

3. BRANDT, A. \& J. INGVERSEN: Isolation and translation of hordein messenger RNA from wild type and mutant endosperms in barley. Carlsberg Res. Commun. 43, 451-469 (1978)

4. Cameron-Mills, V.\& D. von Wettstein: Protein body formation in the developing barley endosperm. Carlsberg Res. Commun. 45, 577-594 (1980)

5. Caughey, I. \& R. G. O. Kekurick: The characteristics of some components of the fatty acid synthetase system in the plastids from the mesocarp of avocado (Persea americana) fruit. Eur. J. Biochem. 123, 553-561 (1982)

6. CHEN,E. Y.\& P. H. SEEBURG: Supercoil sequencing: $A$ fast and simple method for sequencing plasmid DNA. DNA 4, 165-170 (1985)

7. Chirgwin, J. M.. A. E. Przybyla, R. J. MacDonALD \& W. J. RUTTER: Isolation of biologically active ribonucleic acid from sources enriched in ribonuclease. Biochemistry 18, 5294-5299 (1979)

8. COOPER, C. L., S. G. BOYCE \& D. R. LuEKING: Purification and characterization of Rhodobacter sphaeroides acyl carrier protein. Biochemistry 26, 2740-2746 (1987)

9. Davis. L. G.. M. D. Dibner \& J. F. BatTey: Basic Methods in Molecular Biology. Elsevier Science Publ., New York (1986)

10. Dennis, E. S., M. M. Sachs, W. L. Gerlach, E. J. FinNegan \& W. J. Peacock: Molecular analysis of the alcohol dehydrogenase 2 (Adh 2) gene of maize. Nucleic Acids Res. 13, 727-743 (1985)

11. Elhussein, S. A. J. A. Miernyk \& J. B. Ohlrogge: A preliminary characterization of plant holo-acyl carrier protein. In: The Metabolism Structure, and Function of Plant Lipids. P. K. Stumpf, J. B. Mudd and W. D. Nes, eds., Plenum Press, New York, pp. 709-713 (1987)

12. GuerRa, D. J. \& J. B. OHLRogge: Partial purification and characterization of two forms of malonylcoenzyme A:acyl carrier protein transacylase from soybean leaf tissue. Arch. Biochem. Biophys. 246, 274-285 (1986)

13. Hanahan, D.: Techniques for transformation of $E$. coli. In: DNA Cloning vol. 1, a practical approach, ed. D. M. Glover, ed., IRL Press, Oxford, pp. 109-136 (1985)

14. HATTORI, M. \& I. SAKAKI: Dideoxy sequencing method using denatured plasmid templates. Anal.
Biochem. 152, 232-238 (1986)

15. HuYnh, T. V.. R. A. YOUNG \& R. W. Davis: Construction and screening cDNA libraries in $\lambda \mathrm{gt} 10$ and $\lambda g t 11$. In: DNA Cloning vol. 1, a practical approach, D. M. Glover, ed., IRL Press, Oxford, pp. 49-78 (1985)

16. Нøנ,P. B. \& I.SvENDSEN: Barley acyl carrier protein: Its amino acid sequence and assay using purified malonyl-CoA:ACP transacylase. Carlsberg Res. Commun. 48, 285-305 (1983)

17. Høנ, P. B. \& I. SvendSEN: Barley chloroplasts contain two acyl carrier proteins coded for by different genes. Carlsberg Res. Commun. 49, 483-492 (1984)

18. Høyer-Hansen. G.. L. S. Hønberg \& P. B. HøJ: Probing in vitro translation products with monoclonal antibodies to $15.2 \mathrm{kD}$ polypeptide subunit of photosystem I. Carlsberg Res. Commun. 50, 211-221 (1985)

19. Karlin-Neumann, G. A. \& E. M. Tobin: Transit peptides of nuclear-encoded chloroplast proteins share a common amino acid framework. EMBO J. 5, 9-13 (1986)

20. KUO. T. M. \& J. B. OHLRogGE: The primary structure of spinach acyl carrier protein. Arch. Biochem. Biophys. 234, 290-296 (1984)

21. LÜtCKe, H. A., K. C. ChOW. F. S. Mickel, K. A. Moss, H. F. KeRn \& G. A. SCHEEle: Selection of AUG initiation codons differs in plants and animals. EMBO J. 6, 43-48 (1987)

22. Maniatis, T., E. F. Fritsch \& J. SAMbrook: Molecular Cloning. A laboratory Manual. Cold Spring Harbor Laboratory, New York (1982)

23. OHLROGGE, J. B.\& T. M. Kuo: Plants have isoforms for acyl carrier protein that are expressed differently in different tissues. J. Biol. Chem. 260, 80328037 (1985)

24. Ohlrogge, J. B., D. N. Kuhn, P. K. StumpF: Subcellular localization of acyl carrier protein in leaf protoplasts of Spinacia oleracea. Proc. Natl. Acad. Sci. USA 76, 1194-1198 (1979)

25. Ohtsuka, E.. S. Matsuki. M. Ikehara, Y. TaKaHASHI \& K. MATSUBARA: An alternative approach to deoxyoligonucleotides as hybridization probes by insertion of deoxyinosine at ambiguous codon positions. J. Biol. Chem. 260, 2605-2608 (1985)

26. POULSEN.C.: The barley chloroplast genome: physical structure and transcriptional activity in vivo. Carlsberg Res. Commun. 48, 57-80 (1983)

27. QUeEN, C., \& L. J. KORN: A comprehensive sequence analysis program for the IBM personal computer. Nucleic Acids Res. 12, 581-599 (1984)

28. Rose, R. E., C. E. DeJesus, S. L. Moylan, N. P. RidGe, D. E. SChERER \& V. C. KNAUf: The nucleotide sequence of a cDNA clone encoding acyl 
carrier protein (ACP) from Brassica campestris seeds. Nucleic Acids Res. 15, 7197 (1987)

29. SANGer, F., S. Nicklen, A. R. Coulson: DNA sequencing with chain-terminating inhibitors. Proc. Natl. Acad. Sci. USA 74, 5463-5467 (1977)

30. SCHERER, D. E. \& V.C. KNAUF: Isolation of a cDNA clone for the acyl carrier protein-I of spinach. Plant Mol. Biol. 9, 127-134 (1987)

31. SCHMIDT,G.W.\& M.L. MishKIND: The transport of proteins into chloroplasts. Ann. Rev. Biochem. 55, 879-912 (1986)

32. Shimakata, T. \& P. K. STUMPF: Isolation and function of spinach leaf $\beta$-ketoacyl-[acyl-carrierprotein]synthases. Proc. Natl. Acad. Sci. USA 79, 5808-5812 (1982)

33. ShimaKata, T. \& P. K. StumpF: The procaryotic nature of the fatty acid synthetase of developing Carthamus tinctorius L. (Safflower) seeds. Arch. Biochem. Biophys. 217, 144-154 (1982)

34. Slabas, A. R., J. Harding, A. Hellyer, P. Roberts \& H. E. BAMBRIDGE: Induction, purification and characterization of acyl carrier protein from developing seeds of oil seed rape (Brassica napus). Biochim. Biophys. Acta 921, 50-59 (1987)

35. Slabas, A. R., A. Hellyer, C. Sidebottom, H. Bam-
BRIDGE, I. R. COTTINGHAM, R. KESSELL, C. G.SMITH, P. Sheldon, R. G. O. KeKwick, J. de Silva, C. LuCAS, J. Windust, C. M. James, S. G. Hughes \& R. SAFFORD: Molecular structure of plant fatty acid synthesis enzymes. In: Plant Molecular Biology 1987. NATO ASI Series, D. von Wettstein \& N. -H. Chua, eds., Plenum Publ. Co., pp. 265-278 (1987)

36. TABOR, S. \& C. C. Richardson: DNA sequence analysis with a modified bacteriophage T7 DNA polymerase. Proc. Natl. Acad. Sci. USA 84, 47674771 (1987)

37. Vanaman, T. C., S. J. Wakil \& R. L. Hill: The complete amino acid sequence of the acyl carrier protein of Escherichia coli. J. Biol. Chem. 243, 6420-6431 (1968)

38. Williamson, M. J., J. Forde, B. Buxton \& M. KREIS: Nucleotide sequence of barley chymotrypsin inhibitor-2 (Cl-2) and its expression in normal and high-lysine barley. Eur. J. Biochem. 165, 99-106 (1987)

39. Yanisch-Perron, C., J. Vieira \& J. Messing: Improved M13 phage cloning vectors and host strains: nucleotide sequences of the $\mathrm{M} 13 \mathrm{mp} 18$ and pUC19 vectors. Gene 33, 103-119 (1985)

Accepted by S. O. ANDERSEN 